\title{
Region innovative development in the Russian economy technological transformation: ecosystem approach
}

\author{
Artem Salamatov ${ }^{1,2}$, Yuriy Maltsev ${ }^{1 *}$, and Nikita Pavlov ${ }^{1}$ \\ ${ }^{1}$ Chelyabinsk State University, 129 Kashirin Brothers Street, 454001, Chelyabinsk, Russia \\ ${ }^{2}$ Chelyabinsk Branch of the Institute of Economics of the Ural Branch of the Russian Academy of \\ Sciences, 85 Lenina Avenue, 454080, Chelyabinsk, Russia
}

\begin{abstract}
The article considers the ecosystem approach to regional development. The ecosystem approach allows under conditions of technological transformation of the economy to maintain the socioecological-economic balance of the region, to develop the culture and quality of life of the region's population. The structure of ecosystem of the region, the main actors of which are the actors of the system, is considered. By ecosystem we understand a self-organizing, highly adaptive, territorially limited within the natural, institutional, social and political environment network complex of freely cooperating, interacting and mutually influencing each other actors - organizations, processes, projects, services. The core of ecosystems are firms where the first business model prevails and network effects are evident. Russia is in the process of realizing the importance of the ecosystem approach to regional development in the context of technological transformation of the economy. Further development consists in the introduction of "green growth" of the economy, where it is impossible to do without taking into account the ecosystem effects, the development of comprehensive programs for the development of the territory based on the principles of sustainable development.
\end{abstract}

\section{Introduction}

The ecosystem approach implies considering the system of the region as a dynamically developing socio-economic community consisting of actors (players) operating in different sectors of the system, which jointly develop competencies around the innovation with which they work on a cooperative and competitive basis. Ecosystem approach allows under conditions of technological transformation of the economy to maintain the socioecological-economic balance of the region, to develop the culture and quality of life of the region's population.

Ecosystem effects are evaluated in three directions: social - providing balanced decisions and settlement of conflicts between actors; ecological - ability of ecosystems to fulfill their function; and economic - characterizing decision-making of market

\footnotetext{
* Corresponding author: Brazil.yura@mail.ru
} 
management. The ecosystem approach allows to improve the quality of planning of economic activity of the region through the introduction of payment schemes for the use of eco-services; adjustment of natural capital stocks in connection with the depletion of not only resources, but also changes in the functions of ecosystems, which is reflected in the system of national accounts of many developed countries; implementation of payment schemes for different levels of service users [1].

Characteristic of the domestic economy is the borrowing of foreign innovations, technologies, products. Development of own innovation culture, cultivation of value of entrepreneurship as an engine of economy and implementation of new breakthrough ideas is possible with the use of the ecosystem approach.

The socio-economic ecosystem consists of elements located in a limited area of the earth's surface. Therefore, the ecosystem approach is based on communication, network organization, platform, collaboration ("co-competition", "co-creation") of socio-economic actors, the first of which are firms as the most "concentrated" subjects of innovative activity, located almost at all stages of the innovation cycle, in distinguishable (but not constant) physical boundaries of a particular region. Having identified the main actor (but without claiming its dominance), the task of further analysis is to complement and visualize the polysubject model of the region's innovation ecosystem [2].

Ecosystem approach is an interdisciplinary way to present the regional innovation ecosystem as a living organism. The actors of the region are numerous commercial and non-commercial organizations, households, communities, authorities. Authorities are the main actor of the region, responsible for the formation of the institutional environment, the conditions of interaction of economic entities. Research and educational organizations are the actors responsible for the production of innovation in the long term $[3,4]$.

It is worth noting that elements of ecosystems are not limited to one role of an ecosystem subject, they have, so to speak, multifunctional competencies, are able to participate in various ecosystems simultaneously, networks, interaction structures, in some cases forming a multidimensional super-ecosystem (national, global). One and the same person, natural or legal, can combine different actor roles: inspirer, customer, investor, developer, distributor of innovations, consumer, investor, regulator [5].

\section{Materials and Methods}

An ecosystem is also a set of entities that use an innovation platform - a technology, product or service that serves as the basis on which other firms develop additional technologies, products or services. In a broader interpretation, the ecosystem can include all users. This reveals an important feature of the ecosystem approach, "thanks to" which it is necessary to integrate all known elements of the environment into the ecosystem model at some point. The entire external environment - from business partners and consumers to legislation and the economic and political structure of society - is included among the actors of the company's innovation activity.

On the other hand, if we consider the prospects of the near future (for example, the concepts of Smart City, smart-regions), then the ecosystem dynamics can involve all the actors present in the territory of the region [6].

The process of determining the actors, in fact, is the implementation of the technology of strategic management, the study of the external environment $[7,8]$.

A single set of essential actors has common boundaries, similar institutions, communication channels, development principles form the possibility of interpenetration of these sub-ecosystems, aggregate the energy of actors, producing the growth of synergy of social and business efforts of leaders of change. This ecosystem dialectic contributes to the 
growing importance of social responsibility of business and the need to include entrepreneurial technologies in social projects.

The actors of the ecosystem in terms of time and nature of acceptance (non-acceptance) of innovation are: initiators of acceptance (the very first few supporters of innovation), visionaries (formal and informal leaders of the region, actively accepting the innovation), early majority (pragmatists, without much zeal, but accepting innovation), later majority (skeptics, conservatives, forced to accept innovation after the greater community), traditionalists, implementing negative coverage of innovation, their rejection. In addition, within the groups mentioned above there are the most active representatives who form the behavioral image of the entire community ("tardian minorities"), to whom the attention of the initiator and disseminator of innovation should be directed in the first place.

With the possible lightning-fast exchange of information, mass reactions to events and statements in social networks and messengers, the actors previously recognized as bearers of influence are losing their former importance. Power structures, regional financial elites, political leaders and owners of traditional media are looking for new ways to increase and maintain their influence on public opinion.

It should be added that the term ecosystem should be defined a priori in each case: firm, organization, company (in a narrow interpretation) or more broadly (platform, network, region, industry, etc.). This determines the boundary of the external and internal environment of the ecosystem and the strategies necessary for its implementation.

The ecosystem approach is rapidly developing, its principles and terminological base are being elaborated. In this paper, the ecosystem will be understood as a self-organizing, highly adaptive, territorially limited within the natural, institutional, social and political environment network complex of freely cooperating, interacting and mutually influencing elements - organizations, processes, projects, services [9].

\section{Results}

A spatio-temporal view of the ecosystem. Space and time, the most universal characteristics of the world, allow to describe almost any system, including the system of the region with the processes of formation of the digital economy taking place in it. Indeed, the ecosystem of a region is the space in which socio-economic processes unfold. The ecosystem is a space of relations, connections of the subjects (elements) of this space. Time serves as an additional characteristic allowing to measure the speed of ongoing socio-economic transformations. Application of the approach is focused both on revealing the type of economic forms prevailing in the ecosystem, and on assessing the quality of the environment of interactions in the temporal dynamics.

Multilevel assessment of ecosystem elements and management structure. Multilevel structure of ecosystem consisting of micro-level interactions (inter-subjective relations), mesolevel consisting of networks, macro-level (relations between institutions, large communities) and meta-level representing managing influences. This approach allows us to synchronize the directions of development of various components, (conditionally) managed and controlling in the ecosystem of smart communities [10].

The approach provides practical tools for identifying social sources of influence, searching for promising directions of resource flows, and analyzing deviations at different levels of large communities. Unification of values and strategies of various components of large social communities (regions, cities) can be implemented thanks to the service concept of ecosystem, relevant in the deployment of service economy, and the new possibilities of "smart" digital technology.

Evaluation of productivity factors. Following the logic of reflecting new large-scale economic trends in the ecosystem approach, here is an approach based on an analysis of the 
development of the share economy. The traps of today's ecologically destructive predatory type of economy can be overcome by ecosystems of reasonable, if possible, full use of resources. The evaluation of such ecosystems implies a detailed analysis of the efficiency of resource use. The need for such diagnostics is also emphasized by Russian researchers, and with regard to regional innovation systems, which speaks to the universality of the method of assessing the usability of assets.

Indeed, used on average one hour a day personal car in terms of optimal consumption of resources is an example of waste. The widespread implementation of the principles of shared consumption in a number of traditional industries: transportation (Uber), tourism (Booking.com), professional services, shows the prospects of expanding this approach to resource sharing and actualizes the methods for assessing the productivity and usability of resources. Negative consequences of the sharing economy are the collapse of traditional markets, the release of a significant share of labor resources, the withdrawal of state control, but we emphasize that the interest in the maximum use of resources is one of the main objectives of production systems, government, regulatory authorities must find relevant mechanisms to adapt existing methods of state regulation to the requirements of the evolving economy.

A model for assessing the cyclicality of the regional ecosystem. It seems that innovative ecosystems are designed not only to develop and introduce new products, services, services with maximum efficiency, but also with the least possible negative impact on nature. In this regard, the concept under consideration is similar to the previous model, evaluating ecosystems in terms of resource productivity. The peculiarity of the approach is the use of the scientific apparatus of the theory of cyclic (circular) economy, which is increasingly migrating from a predominantly ecological orientation to an innovative competitive business model of cooperation for the sake of common and lossless use of resources. The strategy of lifelong product maintenance, which is gaining popularity in ecosystem theory, also adheres to the latter. From the point of view of ensuring zero-waste production, the important parameters of ecosystem evaluation are:

a) the external environment - customer needs, existing and prospective technologies, institutional changes;

b) business models of actors (how far the models depart from the principles of closedloop economy and what changes are necessary for transformation and integration) [11].

It is noteworthy that practical research has shown the interest of the studied companies to move from resource-intensive business models, focused on the production of a product, to business models aimed at the predominant provision of services [12].

The concept of industrial symbiosis closes the triad of ecosystem evaluation methods, focused on environmental friendliness and efficient performance. Assuming the readiness of modern information technology to analyze previously incalculable data for the entire range of enterprises in the world, the German authors, Anna Lütje and Volker Wohlgemuth [13], suggest extending the closed-loop ecosystem vision to the planetary level. Such a perspective is possible with the spread of industrial symbiosis practices (ideally, all with all, similar to the planetary natural ecosystem), involving mutually beneficial active inter-firm cooperation: mutual training, exchange of materials, resources, technology, common principles of management, collective negotiations, organization of projects, and, ultimately, commonality of goal setting.

The value of the above concept for the task of identifying the range of factors for assessing ecosystem development lies in the study of the ecosystem with artificial intelligence tools based on the analysis of the efficiency of the overall use of resources, both material and social. 
Note that "symbiosis" as well as "ecosystem" is a natural science term. The approach proves the extension of the interdisciplinary nature of the methodology of analysis of socioeconomic processes.

Platform ecosystems. Growth strategies are inherent in both natural ecosystems and socio-ecological-economic ecosystems. Moreover, the development of digital technologies expands opportunities both for intrasectoral growth and the penetration of innovative ecosystems into other markets and niches (a vivid example is the Russian ecosystem Sber). Danish scientist Omar Valdez-de-Leon [14] believes that progress in digitalization will turn any ecosystem of actor interactions into a digital ecosystem, because from the institutional point of view, the main achievement of the digital economy should be the reduction of transaction costs of interaction between independent parties. The proposed methodology is based on a modern system of impact assessment aimed at measuring the effectiveness of innovation ecosystems supported in the European Union. While previously the evaluation of innovative projects financed by the European Union relied on classical economic, scientific and technological indicators, the concept now being built in the evaluation of IES emphasizes their main target - the development of new and promising products, services, services, constant renewal for the survival and development of the ecosystem. Therefore, priority is given to such evaluation factors as innovation readiness of the ecosystem (identification of internal potential for development and implementation of innovations, in direct connection with the study of external environment conditions), innovation management system and market potential of innovations. The latter factor is particularly important for describing ecosystem interactions, the role distribution of actors. Thus, the study showed that although universities often act as a source of innovative products, their introduction to the market takes place through private firms, which indicates different "competence" vectors of ecosystem actors.

Impact assessment. The vector of attention in this approach focuses on the strength, scale and consequences of the cross-influence of ecosystem actors as a factor primarily in social development. The author of the method Jarrod Ormiston [15] includes among the stakeholders commercial and social investors, representatives of government agencies, managers, employees, consultants, clients, various trustees and beneficiaries, representatives of communities.

Impact assessment should be understood as "a transdisciplinary practice that evolves and brings together multiple practices, such as strategy, operational management, accounting, marketing, motivation, and organizational learning. Recognizing that ecosystems are endowed with a kind of unity, commonality the application of narrow approaches to their assessment significantly impoverishes the results of the analysis. Therefore, the key to more accurate results of the study of ecosystems is seen in the further development of integrated tools, synergistic approaches.

The proposed evaluation system is based on a new paradigm of the investment process which, from the perspective of the principles of social responsibility of business, focuses not only and not so much on providing a financial return for investors who invest resources in the development of a particular enterprise, commercial or social project, the ecosystem as a whole, but on the realization of measurable values for society - narrow social, economic, cultural, environmental. Note that for the coverage and dissemination of theories and practices of this kind in Europe is published magazine - Business Ethics, in which the study under consideration by D. Ormiston was published.

Intensity of innovation activity. In development of the previous investment and innovation approaches, the concept of researchers from Ekaterinburg is interesting. This concept divides modern industrial business models into two groups: high-tech (priority is given to innovative technologies) and traditional (priority is given to material resources). And the core of ecosystems are firms where the first business model prevails and network 
effects are evident. Hence, the assessment of the development of industrial ecosystems should be based on the study of the dynamics of the level of technology, innovativeness, transformation of forms of management to high-tech models.

There is some concern that the authors of the concept point to the fact that the growth of the customer base can lead to negative network effects and the need for additional investment in projects. However, it should be noted that the general premise of the study is still aimed at the recognition of the value of the transformation of classical business models into ecosystem ones [16].

The views of Moscow scientists S.P. Zemtsov and A.V. Chernov are similar to this concept. The system of «online reputation» (feedback). As indicated above, the development of information technology and the capabilities of platforms are most responsible for the widespread ecosystem approach in entrepreneurship and science. Digital platforms, acting both as a supporting technological tool for entrepreneurship and as an independent "ecosystem-platform" business model, provide data generation, ecosystem connections, network effects, distribution of resources, products, services [17].

The evaluation of application users has been adopted by most digital platforms as a selfregulatory mechanism. Therefore, it is logical to use (un) structured evaluations of consumers (partners, competitors, other actors) as a basis for ecosystem monitoring. The characteristics represented by consumers (demand conditions) can assess economic variables such as innovation, competition, openness, diversification, and production structure. Feedback in business is nothing new. But thanks to the possibilities of machine systematization and deep processing of feedback, evaluative findings can create additional effects, including learning, adapting (disciplining), integrating (increasing trust) both the "holders" of the platform and all its actors, from consumers to regulators. Indeed, interactivity, permanent feedback is a fundamental condition for self-organization of any ecosystems, including natural ones. Hence, the inversion of assessment is possible: if the feedback does not cause changes, then we are not dealing with an ecosystem, but with a traditional, mechanistic system of relations $[18,19]$.

The methods of the ecosystem approach to the innovative development of the region, given in the work, can be systematized in the form of a table clearly representing the main approaches to ecosystems, the scope of their application and the founders of these approaches. The result of systematization is presented in Table 1.

Table 1. Approaches to Ecosystem Assessment.

\begin{tabular}{|c|c|c|}
\hline Approaches to ecosystem assessment & $\begin{array}{c}\text { Main area of } \\
\text { application }\end{array}$ & Authors \\
\hline $\begin{array}{l}\text { Space (areal) and time (life cycle) are } \\
\text { ontological factors for assessing the level } \\
\text { of ecosystem development as a new } \\
\text { paradigm for considering the main actors } \\
\text { operating in the economy }\end{array}$ & $\begin{array}{l}\text { General } \\
\text { Theory of } \\
\text { Ecosystems }\end{array}$ & Kleiner G.B. \\
\hline $\begin{array}{l}\text { Multilevel assessment of ecosystem } \\
\text { elements and management structure } \\
\text { 1) Micro, meso and macro level of } \\
\text { analysis: identifying and assessing key } \\
\text { actors, technologies, institutions, } \\
\text { resources, values. } \\
\text { 2) Meta-level analysis: the main strategies } \\
\text { used by management to harmonize the } \\
\text { main elements of the ecosystem at the } \\
\text { micro, meso and macro levels }\end{array}$ & $\begin{array}{c}\text { Smart } \\
\text { Community } \\
\text { (Smart City, } \\
\text { Region etc.) }\end{array}$ & $\begin{array}{c}\text { Maria Vincenza } \\
\text { Ciasullo, Orlando Troisi, } \\
\text { Mara Grimaldi \& Daniele } \\
\text { Leone }\end{array}$ \\
\hline $\begin{array}{l}\text { Evaluating the cyclicality of the } \\
\text { ecosystem. Factors for assessing }\end{array}$ & $\begin{array}{l}\text { Zero waste } \\
\text { management }\end{array}$ & $\begin{array}{l}\text { Vinit Paridaa, Thommie } \\
\text { Burströmc, Ivanka Visnjicd, }\end{array}$ \\
\hline
\end{tabular}




\begin{tabular}{|c|c|c|}
\hline $\begin{array}{l}\text { ecosystem readiness (to a zero-waste type } \\
\text { of production): external environment } \\
\text { (customer interests, technological } \\
\text { capabilities, regulatory changes), business } \\
\text { model and partner ecosystems }\end{array}$ & & Joakim Wincenta \\
\hline $\begin{array}{l}\text { The concept of industrial symbiosis: } \\
\text { valuing the ecosystem based on the } \\
\text { efficient overall use of resources, both } \\
\text { material and social }\end{array}$ & $\begin{array}{l}\text { The planetary } \\
\text { scale of } \\
\text { ecosystem } \\
\text { impacts }\end{array}$ & $\begin{array}{l}\text { Anna Lütje, Volker } \\
\text { Wohlgemuth }\end{array}$ \\
\hline $\begin{array}{l}\text { Platform ecosystems. Evaluating the } \\
\text { interaction metrics of organizations that } \\
\text { are digitally connected and allow for } \\
\text { modularity (assessing the impact on } \\
\text { ecosystem expansion). Three key elements } \\
\text { for analysis: platform, network effects and } \\
\text { market expectations }\end{array}$ & $\begin{array}{l}\text { Digital } \\
\text { ecosystems }\end{array}$ & Omar Valdez-de-Leon \\
\hline $\begin{array}{l}\text { Analysis of innovation factors within the } \\
\text { ecosystem (innovation readiness, } \\
\text { innovation management structure, and } \\
\text { innovation market potential) }\end{array}$ & $\begin{array}{l}\text { Regional } \\
\text { innovation } \\
\text { ecosystem } \\
\text { (European } \\
\text { Union) }\end{array}$ & $\begin{array}{c}\text { Daniel Nepelski, Vincent Van } \\
\text { Roy }\end{array}$ \\
\hline $\begin{array}{l}\text { A comprehensive impact assessment of } \\
\text { ecosystem actors that integrates multiple } \\
\text { management practices: strategy, } \\
\text { accounting, marketing, and organizational } \\
\text { development } \\
\end{array}$ & $\begin{array}{l}\text { Scope of } \\
\text { investment }\end{array}$ & Jarrod Ormiston \\
\hline Intensity of innovation activity & $\begin{array}{l}\text { Ecosystems of } \\
\text { high-tech } \\
\text { companies }\end{array}$ & $\begin{array}{c}\text { S.V. Orekhova, A.V. } \\
\text { Misyura, E.V. Kislitsyn, S.P. } \\
\text { Zemtsov, A.V. Chernov }\end{array}$ \\
\hline $\begin{array}{l}\text { The "online reputation" system } \\
\text { (feedback). }\end{array}$ & $\begin{array}{l}\text { Platform-based } \\
\text { innovation } \\
\text { ecosystems }\end{array}$ & $\begin{array}{l}\text { Adilson Giovanini, Pablo F. } \\
\text { Bittencourt, Maurício Uriona } \\
\text { Maldonado }\end{array}$ \\
\hline
\end{tabular}

\section{Conclusions}

Thus, the considered ecosystem approach to innovative regional development allows diagnosing entrepreneurial structures and explaining innovative differences at the regional level. Russia is in the process of realizing the importance of the ecosystem approach to regional development in the technological transformation of the economy. Further development consists in the introduction of "green growth" of the economy, where it is impossible to do without taking into account ecosystem effects, the development of comprehensive programs for the development of the territory based on the principles of sustainable development.

\section{Acknowledgement}

The article was prepared in accordance with the Research Plan of the FSBI "Institute of Economics, Ural Branch of RAS" for 2021.

\section{References}

1. S. Jacobs, N. Dendoncker, H. Keune, Local Practices, Elsevier 411 (2014) doi: 10.1016/j.ecoser.2018.03.006 
2. A. Hein, J. Weking, M. Schreieck et al, Electronic Markets 29(3), 503-518 (2019) doi: 10.1007/s12525-019-00337-y

3. N.A. Serebryakova, N.V. Dorokhova, M.I. Isayenko, Vestnik VSUIT 81(2), 268-273 (2019) doi: 10.20914/2310-1202-2019-4-268-273

4. Y.I. Seliverstov, M.V. Lyuluchenko, Vestnik of the Altai Academy of Economics and Law 10(1), 101-106 (2019) doi: 10.17513/vaael.751

5. Ch.V. Kerimova, Accounting. Analysis. Audit 5(4), 46-55 (2018) doi: 10.26794/24089303-2018-5-4-46-55

6. E.B. Tyutyukina, T.N. Sedash, A.I. Danilov, Business. Education. Law 1(46), 89-94 (2019) doi: 10.25683/VOLBI.2019.46.143

7. L.S. Mazelis, K.S. Solodukhin, K.I. Lavrenyuk, Vestnik of Tyumen State University. Socio-economic and legal research 3(3), 242-260 (2017) doi: 10.21684/2411-78972017-3-3-242-260

8. K.A. Chernov, Vestnik of Volgograd State University. Economics. Ecology 20(4), 4754 (2018) doi: 10.15688/jvolsu3.2018.4.5

9. G.B. Kleiner, Economics and mathematical methods 56(1), 18-33 (2020) doi: $10.31857 / \mathrm{S} 042473880008562-7$

10. G.B. Kleiner, Economic revival of Russia 2(64), 59-69 (2020) doi: 10.37930/19909780-2020-2-64-59-69

11. A. Giovanini, P.F. Bittencourt, M. Uriona, Revista Brasileira de Inovação 19(1), 1-28 (2020) doi: 10.20396/rbi.v19i0.8655371

12. M.V. Ciasullo, O. Troisi, M. Grimaldi, D. Leone, International Entrepreneurship and Manage 16(1), 1167-1195 (2020) doi: 10.1007/s11365-020-00641-6

13. D. Nepelski, V. Van Roy, The Journal of Technology Transfer 5(2), 1-36 (2020) doi: 10.1007/s10961-020-09814-5

14. O. Valdez-De-Leon, Technology Innovation Management Review 9(8), 43-54 (2019) doi:10.22215/timreview/1260

15. J. Ormiston, Business Ethics: A European Review 28(4), 423-440 (2019) doi: 10.5465/AMBPP.2017.14578

16. S.V. Orekhova, A.V. Misyura, E.V. Kislitsyn, Manager 11(4), 43-58 (2020) doi: 10.29141/2218-5003-2020-11-4

17. S.P. Zemtsov, A.V. Chernov, Journal of NEA 1(41), 68-99 (2019) doi: 10.31737/2221-2264-2019-41-1-3

18. B. Kim, E. Kim, D.J. Miller, J.T. Mahoney, Research Policy 45(4), 914-929 (2016) doi: 10.1016/j.respol.2016.01.017

19. V. Barkhatov, E3S Web of Conferences 15002, $210 \quad$ (2020) doi:10.1051/e3sconf/202021015002 